1 Hacettepe Journal of Mathematics and Statistics

$\bigcap$ Volume 46 (4) (2017), 621-628

\title{
Decompositions of continuity for multifunctions
}

\author{
Marian Przemski *
}

\begin{abstract}
Investigations of decompositions of continuity for functions between topological spaces has a large literature, but extension of this topic to multifunctions has not yet been investigated. The aim of the present note is to introduce the study of decompositions of continuity for multifunctions. For this purpose we will generalize the methods introduced by the author in [27] and later used in [9] and in many papers including for example [10] and [23].
\end{abstract}

Keywords: $\quad \mathrm{D}(\mathrm{c}, \alpha)-, \mathrm{D}(\mathrm{c}, \mathrm{s})-, \mathrm{D}(\mathrm{c}, \mathrm{s})$-set, $\alpha$-continuity, decomposition of continuity, upper semi continuity, quasi-continuity, multifunction.

2000 AMS Classification: 54C05, 54C08, 54C60, 58C07.

Received : 21.03.2016 Accepted : 20.06.2016 Doi : 10.15672/HJMS.2017.492

\section{Introduction and preliminaries}

Throughout the present paper, $(X, \tau)$ and $(Y, \xi)$ will denote a topological space with no separation properties assume. Given a nonempty set $\mathrm{Z} \subset \mathrm{X}$, we denote by $\mathcal{P}(Z)$ the power set of $\mathrm{Z}$. For a subset $\mathrm{A}$ of a topological space $(X, \tau)$ we denote by $\mathrm{Cl}(\mathrm{A})$ and Int(A) the closure and the interior of $\mathrm{A}$, respectively. A subset $\mathrm{A} \subset \mathrm{X}$ is said to be $\alpha$-open [21] (resp. semi-open [8], pre-open [16], b-open [2] (or $\gamma$-open [3], or sp-open [9]), $\beta$-open [17] (or ps-open [1]) if $\mathrm{A} \subset \operatorname{Int}(\mathrm{Cl}(\operatorname{Int}(\mathrm{A}))$ ) (resp. $\mathrm{A} \subset \mathrm{Cl}(\operatorname{Int}(\mathrm{A})), \mathrm{A} \subset \operatorname{Int}(\mathrm{Cl}(\mathrm{A})), \mathrm{A}$ $\subset \mathrm{Cl}(\operatorname{Int}(\mathrm{A})) \cup \operatorname{Int}(\mathrm{Cl}(\mathrm{A}))), \mathrm{A} \subset \mathrm{Cl}(\operatorname{Int}(\mathrm{Cl}(\mathrm{A})))$. The family of all $\alpha$-open (resp. semiopen, pre-open, $\gamma$-open, $\beta$-open) sets in $(X, \tau)$ is denoted by $\alpha(\mathrm{X}, \tau)$ (resp. $\mathrm{SO}(\mathrm{X}, \tau)$, $\mathrm{PO}(\mathrm{X}, \tau), \gamma(\mathrm{X}, \tau), \beta(\mathrm{X}, \tau))$. The union of all $\alpha$-open (resp. semi-open, pre-open, $\gamma$-open, $\beta$-open) sets of $\mathrm{X}$ contained in $\mathrm{A}$ is called $\alpha$-interior (resp. semi-interior, preinterior, $\gamma$ interior, $\beta$-interior) of $\mathrm{A}$ and is denoted by $\alpha \cdot \operatorname{Int}(\mathrm{A})(\operatorname{resp} . \operatorname{s.Int}(\mathrm{A}), \mathrm{p} \cdot \operatorname{Int}(\mathrm{A}), \gamma \cdot \operatorname{Int}(\mathrm{A})($ or s.p.Int(A)[9]), $\beta$.Int(A)(or p.s.Int(A)[9])). The following results will be useful later.

Lemma 1.1[2]. The following hold for a subset $\mathrm{A}$ of a topological space $(X, \tau)$ :

(a) $\alpha \cdot \operatorname{Int}(\mathrm{A})=\mathrm{A} \cap \operatorname{Int}(\mathrm{Cl}(\operatorname{Int}(\mathrm{A})))$;

(b) s.Int $(\mathrm{A})=\mathrm{A} \cap \mathrm{Cl}(\operatorname{Int}(\mathrm{A}))$;

${ }^{*}$ Lomza State University of Applied Sciences (LSUAS) Institute of Computer Science and Automation Akademicka Street 14, 18-400 Lomic, Poland

Email : mprzemski@pwsip.edu.pl 
(c) $p \cdot \operatorname{Int}(\mathrm{A})=\mathrm{A} \cap \operatorname{Int}(\mathrm{Cl}(\mathrm{A}))$;

(d) $\gamma \cdot \operatorname{Int}(\mathrm{A})=\mathrm{s} \cdot \operatorname{Int}(\mathrm{A}) \cup \mathrm{p} \cdot \operatorname{Int}(\mathrm{A})$;

(e) $\beta \operatorname{Int}(\mathrm{A})=\mathrm{A} \cap \mathrm{Cl}(\operatorname{Int}(\mathrm{Cl}(\mathrm{A})))$.

By a multifunction $\mathrm{F}: \mathrm{X} \rightarrow \mathrm{Y}$ we mean a map defined on $\mathrm{X}$ with values being nonempty subsets of Y. Following [4] we shall denote the upper and lower inverse images of a set $\mathrm{B} \subset \mathrm{Y}$ by $\mathrm{F}^{+}(\mathrm{B})$ and $\mathrm{F}^{-}(\mathrm{B})$, respectively, that is, $\mathrm{F}^{+}(\mathrm{B})=\{x \in X: F(x) \subset B\}$ and $\mathrm{F}^{-}(\mathrm{B})=\{x \in X: F(x) \cap B \neq \emptyset\}$. A multifunction $\mathrm{F}:(\mathrm{X}, \tau) \rightarrow(\mathrm{Y}, \xi)$ is called upper semi continuous (briefly u.s.c.) (resp. lower semi continuous (briefly l.s.c.)) [13, 22] at a point $\mathrm{x} \in \mathrm{X}$ if, $\mathrm{x} \in \operatorname{Int}\left(\mathrm{F}^{+}(\mathrm{W})\right.$ ) (resp. $\mathrm{x} \in \operatorname{Int}\left(\mathrm{F}^{-}(\mathrm{W})\right)$ ) for each open subset $\mathrm{W}$ of $\mathrm{Y}$ such that $\mathrm{x} \in \mathrm{F}^{+}(\mathrm{W})$ (resp. $\mathrm{x} \in \mathrm{F}^{-}(\mathrm{W})$ ). It is called u.s.c. (resp. l.s.c.) if $\mathrm{F}$ is u.s.c. (resp. l.s.c.) at each point of $\mathrm{X}$.

There are many generalizations and modifications of continuity. The basic of these are as follows:

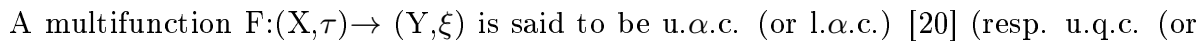

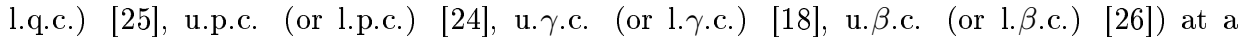
point $\mathrm{x} \in \mathrm{X}$ if, $\mathrm{x} \in \alpha \cdot \operatorname{Int}\left(\mathrm{F}^{+}(\mathrm{W})\right)\left(\right.$ or $\left.\mathrm{x} \in \alpha \cdot \operatorname{Int}\left(\mathrm{F}^{-}(\mathrm{W})\right)\right)\left(\operatorname{resp} . \mathrm{x} \in \operatorname{s.Int}\left(\mathrm{F}^{+}(\mathrm{W})\right)\right.$ (or $\left.\mathrm{x} \in \mathrm{s} \cdot \operatorname{Int}\left(\mathrm{F}^{-}(\mathrm{W})\right)\right), \mathrm{x} \in \mathrm{p} \cdot \operatorname{Int}\left(\mathrm{F}^{+}(\mathrm{W})\right)\left(\right.$ or $\left.\mathrm{x} \in \mathrm{p} \cdot \operatorname{Int}\left(\mathrm{F}^{-}(\mathrm{W})\right)\right), \mathrm{x} \in \gamma \cdot \operatorname{Int}\left(\mathrm{F}^{+}(\mathrm{W})\right)($ or $\mathrm{x}$ $\left.\in \gamma \cdot \operatorname{Int}\left(\mathrm{F}^{-}(\mathrm{W})\right)\right), \mathrm{x} \in \beta \cdot \operatorname{Int}\left(\mathrm{F}^{+}(\mathrm{W})\right)\left(\right.$ or $\left.\mathrm{x} \in \beta \cdot \operatorname{Int}\left(\mathrm{F}^{-}(\mathrm{W})\right)\right)$ ) for each $\mathrm{W} \in \xi$ such that $\mathrm{x}$ $\in \mathrm{F}^{+}(\mathrm{W})\left(\right.$ or $\left.\mathrm{x} \in \mathrm{F}^{-}(\mathrm{W})\right)$.

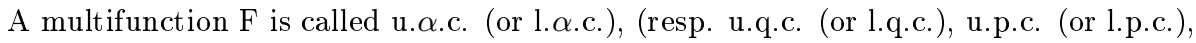

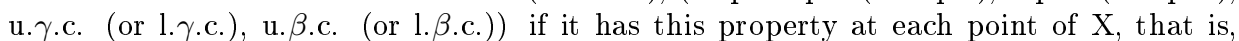
$\mathrm{A} \subset \alpha \cdot \operatorname{Int}(\mathrm{A})($ or $\mathrm{B} \subset \alpha \cdot \operatorname{Int}(\mathrm{B}))($ resp. $\mathrm{A} \subset \mathrm{s} \cdot \operatorname{Int}(\mathrm{A})($ or $\mathrm{B} \subset \mathrm{s} \cdot \operatorname{Int}(\mathrm{B})), \mathrm{A} \subset \mathrm{p} \cdot \operatorname{Int}(\mathrm{A})$ (or $\mathrm{B} \subset$ p.Int(B)), $\mathrm{A} \subset \gamma \cdot \operatorname{Int}(\mathrm{A})$ ( or $\mathrm{B} \subset \gamma \cdot \operatorname{Int}(\mathrm{B}), \mathrm{A} \subset \beta \cdot \operatorname{Int}(\mathrm{A})$ (or $\mathrm{B} \subset \beta \cdot \operatorname{Int}(\mathrm{B}))$ ) for any pair $(\mathrm{A}, \mathrm{B}) \in \mathcal{P}(X) \times \mathcal{P}(X)$ of the form $(\mathrm{A}, \mathrm{B})=\left(\mathrm{F}^{+}(\mathrm{W}), \mathrm{F}^{-}(\mathrm{W})\right)$, where $\mathrm{W} \in \xi$; equivalently, $\mathrm{A} \subset \operatorname{Int}(\mathrm{Cl}(\operatorname{Int}(\mathrm{A}))$ ) (or $\mathrm{B} \subset \operatorname{Int}(\mathrm{Cl}(\operatorname{Int}(\mathrm{B}))$ ), (resp. $\mathrm{A} \subset \mathrm{Cl}(\operatorname{Int}(\mathrm{A})$ ), (or B $\subset \mathrm{Cl}(\operatorname{Int}(\mathrm{B}))), \mathrm{A} \subset \operatorname{Int}(\mathrm{Cl}(\mathrm{A}))$, (or B $\subset \operatorname{Int}(\mathrm{Cl}(\mathrm{B}))), \mathrm{A} \subset \mathrm{Cl}(\operatorname{Int}(\mathrm{A})) \cup \operatorname{Int}(\mathrm{Cl}(\mathrm{A}))$, (or B $\subset \mathrm{Cl}(\operatorname{Int}(\mathrm{B})) \cup \operatorname{Int}(\mathrm{Cl}(\mathrm{B}))), \mathrm{A} \subset \mathrm{Cl}(\operatorname{Int}(\mathrm{Cl}(\mathrm{A})))$, (or $\mathrm{B} \subset \mathrm{Cl}(\operatorname{Int}(\mathrm{Cl}(\mathrm{B}))))$ ) for any pair $(\mathrm{A}, \mathrm{B}) \in \mathcal{P}(X) \times \mathcal{P}(X)$ of the form $(\mathrm{A}, \mathrm{B})=\left(\mathrm{F}^{+}(\mathrm{W}), \mathrm{F}^{-}(W)\right)$, where $\mathrm{W} \in \xi$.

Of course, if a single-valued function $\mathrm{f}:(\mathrm{X}, \tau) \rightarrow(\mathrm{Y}, \xi)$ is treated as a multifunction $\mathrm{F}$ given by $\mathrm{F}(\mathrm{x})=\{f(x)\}$ for all $\mathrm{x} \in X$, then the multifunction $\mathrm{F}$ is u.s.c or l.s.c. (resp.

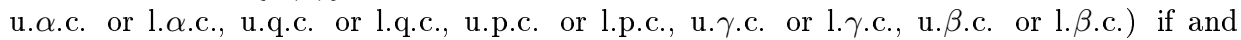
only if the function $\mathrm{f}$ is continuous (resp. $\alpha$-continuous [15], semi-continuous [11], [14], pre-continuous [16], $\gamma$-continuous [3], $\beta$-continuous [17]) because of the simple fact that in this case we have $\mathrm{F}^{+}(\mathrm{B})=\mathrm{F}^{-}(\mathrm{B})=f^{-1}(\mathrm{~B})$ for any $\mathrm{B} \subset \mathrm{Y}$.

Since any open subset $\mathrm{W} \subset \mathrm{Y}$ designate a pair $\left(\mathrm{F}^{+}(\mathrm{W}), \mathrm{F}^{-}(\mathrm{W})\right) \in \mathcal{P}(X) \times \mathcal{P}(X)$, it is convenient to use the following general concept:

Definition 1.2. Let $\mathcal{R}$ be a binary relation on $\mathcal{P}(\mathrm{X})$. We say that a multifunction $\mathrm{F}:(\mathrm{X}, \tau) \rightarrow(\mathrm{Y}, \xi)$ is $\mathcal{R}$-continuous if $\left(\mathrm{F}^{+}(\mathrm{W}), \mathrm{F}^{-}(\mathrm{W})\right) \in \mathcal{R}$ for any $\mathrm{W} \in \xi$.

Remark 1.3. If we denote

$$
\begin{aligned}
& \tau_{c}^{u}=\tau \times \mathcal{P}(\mathrm{X})\left(\text { or } \tau_{c}^{l}=\mathcal{P}(\mathrm{X}) \times \tau\right)(\text { resp. } \\
& \tau_{\alpha}^{u}=\alpha(\mathrm{X}, \tau) \times \mathcal{P}(\mathrm{X})\left(\text { or } \tau_{\alpha}^{l}=\mathcal{P}(\mathrm{X}) \times \alpha(\mathrm{X}, \tau)\right) \text {, } \\
& \tau_{s}^{u}=\mathrm{SO}(\mathrm{X}, \tau) \times \mathcal{P}(\mathrm{X})\left(\text { or } \tau_{s}^{l}=\mathcal{P}(\mathrm{X}) \times \mathrm{SO}(\mathrm{X}, \tau)\right) \text {, } \\
& \tau_{p}^{u}=\mathrm{PO}(\mathrm{X}, \tau) \times \mathcal{P}(\mathrm{X})\left(\text { or } \tau_{p}^{l}=\mathcal{P}(\mathrm{X}) \times \mathrm{PO}(\mathrm{X}, \tau)\right) \text {, } \\
& \tau_{\gamma}^{u}=\gamma \mathrm{O}(\mathrm{X}, \tau) \times \mathcal{P}(\mathrm{X})\left(\text { or } \tau_{\gamma}^{l}=\mathcal{P}(\mathrm{X}) \times \gamma \mathrm{O}(\mathrm{X}, \tau)\right) \text {, } \\
& \tau_{\beta}^{u}=\beta \mathrm{O}(\mathrm{X}, \tau) \times \mathcal{P}(\mathrm{X})\left(\text { or } \tau_{\beta}^{l}=\mathcal{P}(\mathrm{X}) \times \beta \mathrm{O}(\mathrm{X}, \tau)\right) \text { ), then } \tau_{c}^{u} \text {-continuity (or } \tau_{c}^{l} \text {-continuity) } \\
& \text { (resp. } \tau_{\alpha}^{u} \text {-continuity (or } \tau_{\alpha}^{l} \text {-continuity), } \tau_{s}^{u} \text {-continuity (or } \tau_{s}^{l} \text {-continuity), } \tau_{p}^{u} \text {-continuity } \\
& \text { (or } \tau_{p}^{l} \text {-continuity), } \tau_{\gamma}^{u} \text {-continuity (or } \tau_{\gamma}^{l} \text {-continuity), } \tau_{\beta}^{u} \text {-continuity (or } \tau_{\beta}^{l} \text {-continuity)) is }
\end{aligned}
$$

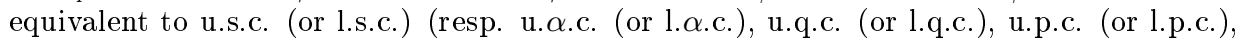




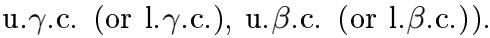

In this present paper we consider a special type of continuity for multifunctions, named in the literature "minimality", or type "lu" and defined as follows.

Definition 1.4. A multifunction $\mathrm{F}:(\mathrm{X}, \tau) \rightarrow(\mathrm{Y}, \xi)$ is said to be:

(a) lu.s.c. if $\mathrm{F}^{-}(\mathrm{W}) \subset \operatorname{Int}\left(\mathrm{F}^{+}(\mathrm{W})\right.$ for each $\mathrm{W} \in \xi$;

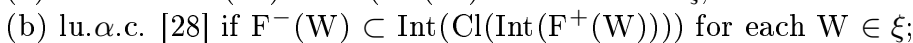

(c) lu.q.c. $[7,5,6,12,19]$ if $\mathrm{F}^{-}(\mathrm{W}) \subset \mathrm{Cl}\left(\operatorname{Int}\left(\mathrm{F}^{+}(\mathrm{W})\right)\right)$ for each $\mathrm{W} \in \xi$;

(d) lu.p.c. [28] if $\mathrm{F}^{-}(\mathrm{W}) \subset \operatorname{Int}\left(\mathrm{Cl}\left(\mathrm{F}^{+}(\mathrm{W})\right)\right)$ for each $\mathrm{W} \in \xi$;

(e) lu. $\gamma$.c. if $\mathrm{F}^{-}(\mathrm{W}) \subset \mathrm{Cl}\left(\operatorname{Int}\left(\mathrm{F}^{+}(\mathrm{W})\right)\right) \cup \operatorname{Int}\left(\mathrm{Cl}\left(\mathrm{F}^{+}(\mathrm{W})\right)\right)$ for each $\mathrm{W} \in \xi$;

(f) lu. $\beta$.c. [28] if $\mathrm{F}^{-}(\mathrm{W}) \subset \mathrm{Cl}\left(\operatorname{Int}\left(\mathrm{Cl}\left(\mathrm{F}^{+}(\mathrm{W})\right)\right)\right)$ for each $\mathrm{W} \in \xi$.

The property lu.q.c. has been investigated in [7, Theorem 5.2] and in [5, 6, 12, 19] under the name of minimality of multifunctions.

\section{Decompositions of continuity of type "lu"}

In this paper we will generalize the methods introduced in [27]. We begin by defining some useful notions specific for investigations of strictly multi-valued functions. By $\mathcal{P}(X) \overrightarrow{\times} \mathcal{P}(X)$ we denote the set of all pairs $($ A,B $) \in \mathcal{P}(X) \times \mathcal{P}(X)$ satisfying A $\subset \mathrm{B}$.

Definition 2.1. Given a topological space $(\mathrm{X}, \tau)$ we define the following operators $\mathcal{P}(X) \overrightarrow{\times} \mathcal{P}(X) \rightarrow \mathcal{P}(X):$

(a) $\operatorname{Int}_{u}(\mathrm{~A}, \mathrm{~B})=\mathrm{B} \cap \operatorname{Int}(\mathrm{A})$;

(b) $\alpha \cdot \operatorname{Int}_{u}(\mathrm{~A}, \mathrm{~B})=\mathrm{B} \cap \operatorname{Int}(\mathrm{Cl}(\operatorname{Int}(\mathrm{A})))$;

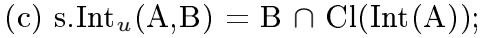

(d) $\operatorname{p.Int}_{u}(\mathrm{~A}, \mathrm{~B})=\mathrm{B} \cap \operatorname{Int}(\mathrm{Cl}(\mathrm{A}))$;

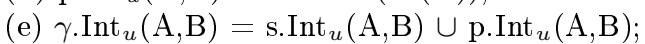

(f) $\beta \cdot \operatorname{Int}_{u}(\mathrm{~A}, \mathrm{~B})=\mathrm{B} \cap \mathrm{Cl}(\operatorname{Int}(\mathrm{Cl}(\mathrm{A})))$.

It is easy to see that the operators in Lemma 1.1 are compositions of the above operators and the diagonal operator $\Delta_{\mathcal{P}(X)}: \mathcal{P}(X) \rightarrow \mathcal{P}(X) \times \mathcal{P}(X)$ given by $\Delta_{\mathcal{P}(X)}(\mathrm{A})$ $=(\mathrm{A}, \mathrm{A})$ for any $\mathrm{A} \in \mathcal{P}(X)$. More precisely:

Remark 2.2. The following hold for a subset A of a topological space $(X, \tau)$ :

(a) $\operatorname{Int}_{u}(\mathrm{~A}, \mathrm{~A})=\operatorname{Int}(\mathrm{A})$;

(b) $\alpha \cdot \operatorname{Int}_{u}(\mathrm{~A}, \mathrm{~A})=\alpha \cdot \operatorname{Int}(\mathrm{A})$;

(c) $\operatorname{s.Int}_{u}(\mathrm{~A}, \mathrm{~A})=\mathrm{s} \cdot \operatorname{Int}(\mathrm{A})$;

(d) $\operatorname{p.Int}_{u}(\mathrm{~A}, \mathrm{~A})=\mathrm{p} \cdot \operatorname{Int}(\mathrm{A})$;

(e) $\gamma \cdot \operatorname{Int}_{u}(\mathrm{~A}, \mathrm{~A})=\gamma \cdot \operatorname{Int}(\mathrm{A})$;

(f) $\beta \cdot \operatorname{Int}_{u}(\mathrm{~A}, \mathrm{~A})=\beta \cdot \operatorname{Int}(\mathrm{A})$.

Definition 2.3. For a topological space $(X, \tau)$ we denote:

(a) $\pi_{c}^{l u}=\left\{(A, B) \in \mathcal{P}(X) \times \mathcal{P}(X): B=\operatorname{Int}_{u}(A, B)\right\}$;

(b) $\pi_{\alpha}^{l u}=\left\{(A, B) \in \mathcal{P}(X) \times \mathcal{P}(X): B=\alpha . \operatorname{Int}_{u}(A, B)\right\}$;

(c) $\pi_{s}^{l u}=\left\{(A, B) \in \mathcal{P}(X) \times \mathcal{P}(X): B=\right.$ s.Int $\left._{u}(A, B)\right\}$;

(d) $\pi_{p}^{l u}=\left\{(A, B) \in \mathcal{P}(X) \times \mathcal{P}(X): B=p \cdot \operatorname{Int}_{u}(A, B)\right\}$;

(e) $\pi_{\gamma}^{l u}=\left\{(A, B) \in \mathcal{P}(X) \times \mathcal{P}(X): B=\gamma \cdot \operatorname{Int}_{u}(A, B)\right\}$;

(f) $\pi_{\beta}^{l u}=\{(A, B) \in \mathcal{P}(X) \times \mathcal{P}(X): B=\beta$.Int $u(A, B)\}$.

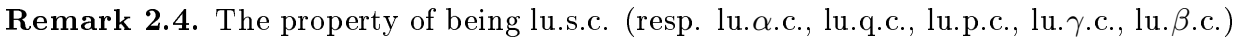


is equivalent to $\tau_{c}^{l u}$-continuity (resp. $\tau_{\alpha}^{l u}$-continuity, $\tau_{s}^{l u}$-continuity, $\tau_{p}^{l u}$-continuity, $\tau_{\gamma}^{l u}-$ continuity, $\tau_{\beta}^{l u}$-continuity).

The following families of subsets were used to obtain standard types of decompositions of continuity and generalized continuity.

Definition 2.5. $[27,9]$ For a topological space $(X, \tau)$ we denote:

(a) $\mathrm{D}(\mathrm{c}, \alpha)=\{A \in \mathcal{P}(X): \operatorname{Int}(A)=\alpha \cdot \operatorname{Int}(A)\}$;

(b) $\mathrm{D}(\mathrm{c}, \mathrm{s})=\{A \in \mathcal{P}(X): \operatorname{Int}(A)=\operatorname{sint}(A)\}$;

(c) $\mathrm{D}(\mathrm{c}, \mathrm{p})=\{A \in \mathcal{P}(X): \operatorname{Int}(A)=p \cdot \operatorname{Int}(A)\}$;

(d) $\mathrm{D}(\mathrm{c}, \beta)=\{A \in \mathcal{P}(X): \operatorname{Int}(A)=\beta \cdot \operatorname{Int}(A)\}$;

(e) $\mathrm{D}(\alpha, \mathrm{s})=\{A \in \mathcal{P}(X): \alpha \cdot \operatorname{Int}(A)=\operatorname{s.Int}(A)\}$;

(f) $\mathrm{D}(\alpha, \mathrm{p})=\{A \in \mathcal{P}(X): \alpha \cdot \operatorname{Int}(A)=p \cdot \operatorname{Int}(A)\}$;

(g) $\mathrm{D}(\alpha, \beta)=\{A \in \mathcal{P}(X): \alpha \cdot \operatorname{Int}(A)=\beta \cdot \operatorname{Int}(A)\}$;

(h) $\mathrm{D}(\mathrm{p}, \gamma)=\{A \in \mathcal{P}(X): p \cdot \operatorname{Int}(A)=\gamma \cdot \operatorname{Int}(A)\}$;

(i) $\mathrm{D}(\mathrm{p}, \beta)=\{A \in \mathcal{P}(X): p \cdot \operatorname{Int}(A)=\beta \cdot \operatorname{Int}(A)\}$;

(j) $\mathrm{D}(\gamma, \beta)=\{A \in \mathcal{P}(X): \gamma \cdot \operatorname{Int}(A)=\beta \cdot \operatorname{Int}(A)\}$.

Each of the above families is of the form $\left\{A \in \mathcal{P}(X): O_{1}(A)=O_{2}(A)\right\}$, that is, the set of coincidence points of a pair $\left(O_{1}, O_{2}\right)$ of different operators $O_{1}, O_{2}: \mathcal{P}(X) \rightarrow \mathcal{P}(\mathrm{X})$ which are members of the collection $\{$ Int, $\alpha$.Int, p.Int, s.Int, $\gamma$.Int, $\beta$.Int $\}$. In the case of operators $\mathrm{O}: \mathcal{P}(X) \overrightarrow{\times} \mathcal{P}(X) \rightarrow \mathcal{P}(X)$ introduced in Definition 2.1 , we get the general result. Before starting, we need a specific operator $\mathrm{I}_{l}: \mathcal{P}(X) \times$ $\mathcal{P}(X) \rightarrow \mathcal{P}(X)$ defined by $\mathrm{I}_{l}(\mathrm{~A}, \mathrm{~B})=\mathrm{B}$.

Theorem 2.6. Let $(X, \tau)$ be a topological space. Any set of coincidence points of a pair $\left(O_{1}, O_{2}\right)$ of different operators belonging to the following collection

$\left\{\right.$ Int $_{u}, \alpha$. Int $_{u}$, s.Int $_{u}, p$. Int $_{u}, \gamma$. Int $_{u}, \beta$. Int $\left._{u}, I_{l}\right\}$ is equal to one of the following:

(a) $\tau_{c}^{l u}, \tau_{\alpha}^{l u}, \tau_{s}^{l u}, \tau_{p}^{l u}, \tau_{\gamma}^{l u}, \tau_{\beta}^{l u}$;

(b) $\mathcal{D}^{l u}(\mathrm{c}, \alpha)=\left\{(A, B) \in \mathcal{P}(X) \times \mathcal{P}(X): \operatorname{Int}_{u}(A, B)=\alpha \cdot \operatorname{Int}_{u}(A, B)\right\}$;

(c) $\mathcal{D}^{l u}(\mathrm{c}, \mathrm{s})=\left\{(A, B) \in \mathcal{P}(X) \times \mathcal{P}(X): \operatorname{Int}_{u}(A, B)=\right.$ s.Int $\left._{u}(A, B)\right\}$;

(d) $\mathcal{D}^{l u}(\mathrm{c}, \mathrm{p})=\left\{(A, B) \in \mathcal{P}(X) \times \mathcal{P}(X): \operatorname{Int}_{u}(A, B)=\right.$ p.Int $\left._{u}(A, B)\right\}$;

(e) $\mathcal{D}^{l u}(\mathrm{c}, \beta)=\left\{(A, B) \in \mathcal{P}(X) \times \mathcal{P}(X): \operatorname{Int}_{u}(A, B)=\beta\right.$.Int $\left.u(A, B)\right\}$;

(f) $\mathcal{D}^{l u}(\alpha, \mathrm{s})=\left\{(A, B) \in \mathcal{P}(X) \times \mathcal{P}(X): \alpha\right.$ Int $_{u}(A, B)=$ s.Int $\left._{u}(A, B)\right\}$;

(g) $\mathcal{D}^{l u}(\alpha, \mathrm{p})=\left\{(A, B) \in \mathcal{P}(X) \times \mathcal{P}(X): \alpha \cdot \operatorname{Int}_{u}(A, B)=\right.$ p.Int $\left._{u}(A, B)\right\}$;

(h) $\mathcal{D}^{l u}(\alpha, \beta)=\left\{(A, B) \in \mathcal{P}(X) \times \mathcal{P}(X): \alpha \cdot \operatorname{Int}_{u}(A, B)=\beta \cdot \operatorname{Int}_{u}(A, B)\right\}$;

(i) $\mathcal{D}^{l u}(\mathrm{p}, \gamma)=\left\{(A, B) \in \mathcal{P}(X) \times \mathcal{P}(X):\right.$ p.Int $\left._{u}(A, B)=\gamma \cdot \operatorname{Int}_{u}(A, B)\right\}$;

(j) $\mathcal{D}^{l u}(\mathrm{p}, \beta)=\left\{(A, B) \in \mathcal{P}(X) \times \mathcal{P}(X): p \cdot \operatorname{Int}_{u}(A, B)=\beta \operatorname{Int}_{u}(A, B)\right\}$;

(k) $\mathcal{D}^{l u}(\gamma, \beta)=\left\{(A, B) \in \mathcal{P}(X) \times \mathcal{P}(X): \gamma \cdot \operatorname{Int}_{u}(A, B)=\beta \cdot \operatorname{Int}_{u}(A, B)\right\}$.

Proof. It is clear that the sests in (a) are designated by the pairs $\left(I_{l}\right.$, Int $\left._{u}\right),\left(I_{l}, \alpha\right.$. Int $\left._{u}\right)$, $\left(I_{l}\right.$, s.Int $\left.u\right),\left(I_{l}, p\right.$. Int $\left._{u}\right),\left(I_{l}, \gamma\right.$. Int $\left._{u}\right)$ and $\left(I_{l}, \beta\right.$. Int $\left._{u}\right)$, respectively. Analogously, the sets $\mathcal{D}^{l u}(\mathrm{c}, \alpha), \mathcal{D}^{l u}(\mathrm{c}, \mathrm{s}), \mathcal{D}^{l u}(\mathrm{c}, \mathrm{p})$ and $\mathcal{D}^{l u}(\mathrm{c}, \beta)$ are designated by the pairs $\left(\right.$ Int $_{u}, \alpha$. Int $\left._{u}\right)$, $\left(\right.$ Int $_{u}$, s.Int $\left.t_{u}\right),\left(\right.$ Int $_{u}, p$. Int $\left._{u}\right)$ and $\left(\right.$ Int $_{u}, \beta \cdot$ Int $\left._{u}\right)$, respectively. Now we show that the pairs $\left(\right.$ Int $_{u}, \beta$. Int $\left._{u}\right)$ and $\left(\right.$ Int $_{u}, \gamma$. Int $\left.t_{u}\right)$ have the same set of coincidence points. Indeed, if $\gamma \cdot \operatorname{Int}_{u}(\mathrm{~A}, \mathrm{~B}) \subset \operatorname{Int}_{u}(\mathrm{~A}, \mathrm{~B})$, i.e., $(\mathrm{B} \cap \mathrm{Cl}(\operatorname{Int}(\mathrm{A}))) \cup(\mathrm{B} \cap \operatorname{Int}(\mathrm{Cl}(\mathrm{A}))) \subset \mathrm{B} \cap \operatorname{Int}(\mathrm{A})$, then $\mathrm{Cl}(\mathrm{B} \cap \operatorname{Int}(\mathrm{Cl}(\mathrm{A}))) \subset \mathrm{Cl}(\mathrm{B} \cap \operatorname{Int}(\mathrm{A}))$ and consequently, $\mathrm{Cl}(\operatorname{Int}(\mathrm{Cl}(\mathrm{A})))=\mathrm{Cl}(\operatorname{Int}(\mathrm{A}))$ because of $\mathrm{Cl}(\mathrm{B} \cap \operatorname{Int}(\mathrm{Cl}(\mathrm{A}))=\mathrm{Cl}(\mathrm{Cl}(\mathrm{B}) \cap \operatorname{Int}(\mathrm{Cl}(\mathrm{A}))$ and $\mathrm{A} \subset \mathrm{B}$. As a result, we obtain $(\mathrm{B} \cap \mathrm{Cl}(\operatorname{Int}(\mathrm{A}))) \cup(\mathrm{B} \cap \operatorname{Int}(\mathrm{Cl}(\mathrm{A})))=\mathrm{B} \cap \mathrm{Cl}(\operatorname{Int}(\mathrm{Cl}(\mathrm{A}))) \subset \operatorname{Int}_{u}(\mathrm{~A}, \mathrm{~B})$. This means that $\operatorname{Int}_{u}(\mathrm{~A}, \mathrm{~B})=\beta$. $\operatorname{Int}_{u}(\mathrm{~A}, \mathrm{~B})$. So, the sets in (b), (c), (d) and (e) are the only sets of coincidence points that can be obtained by use of the operator $\operatorname{Int}_{u}$. Since $\mathrm{Cl}(\operatorname{Int}(\mathrm{A})$ ) $=\mathrm{Cl}(\operatorname{Int}(\mathrm{Cl}(\operatorname{Int}(\mathrm{A}))))$, analogously one can show that $\alpha \cdot \operatorname{Int}_{u}(\mathrm{~A}, \mathrm{~B})=\beta \cdot \operatorname{Int}_{u}(\mathrm{~A}, \mathrm{~B})$ and 
$\alpha \cdot \operatorname{Int}_{u}(\mathrm{~A}, \mathrm{~B})=\gamma \cdot \operatorname{Int}_{u}(\mathrm{~A}, \mathrm{~B})$ are equivalent. So, the sets in (f), (g), (h) and (b) are the only sets of coincidence points that can be obtained by use of the operator $\alpha \cdot \operatorname{Int}_{u}$. To prove that the sets in $(\mathrm{i}),(\mathrm{j}),(\mathrm{d})$ and $(\mathrm{g})$ are the only sets of coincidence points that can be obtained by use of the operator p.Int ${ }_{u}$, we will show that $\mathrm{p} \cdot \operatorname{Int}_{u}(\mathrm{~A}, \mathrm{~B})=\mathrm{s}_{\operatorname{Int}}(\mathrm{A}, \mathrm{B})$ and $\alpha \cdot \operatorname{Int}_{u}(\mathrm{~A}, \mathrm{~B})=\beta \cdot \operatorname{Int}_{u}(\mathrm{~A}, \mathrm{~B})$ are equivalent. If $\mathrm{p} \cdot \operatorname{Int}_{u}(\mathrm{~A}, \mathrm{~B})=\mathrm{s} \operatorname{Int}_{u}(\mathrm{~A}, \mathrm{~B})$, then of course,

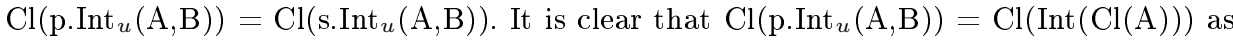
shown in the previous part of the proof. Now we show that $\mathrm{Cl}\left(\mathrm{s}^{-I_{n}}{ }_{u}(\mathrm{~A}, \mathrm{~B})\right)=\mathrm{Cl}(\operatorname{Int}(\mathrm{A}))$. Indeed, $\mathrm{Cl}(\mathrm{B} \cap \operatorname{Int}(\mathrm{A})) \subset \mathrm{Cl}\left(\mathrm{s}_{\operatorname{Int}}(\mathrm{A}, \mathrm{B})\right) \subset \mathrm{Cl}(\operatorname{Int}(\mathrm{A}))$ and of course, $\mathrm{Cl}(\mathrm{B} \cap \operatorname{Int}(\mathrm{A}))=$ $\mathrm{Cl}(\operatorname{Int}(\mathrm{A}))$. Consequently, $\mathrm{B} \cap \operatorname{Int}(\mathrm{Cl}(\operatorname{Int}(\mathrm{A})))=\mathrm{B} \cap \operatorname{Int}(\mathrm{Cl}(\mathrm{A}))$ and $\mathrm{B} \cap \mathrm{Cl}(\operatorname{Int}(\mathrm{A}))=$

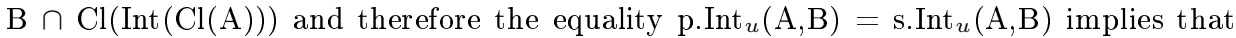
$\alpha \cdot \operatorname{Int}_{u}(\mathrm{~A}, \mathrm{~B})=\beta \cdot \operatorname{Int}_{u}(\mathrm{~A}, \mathrm{~B})$. Conversely, the last equality implies that $\operatorname{p.Int}_{u}(\mathrm{~A}, \mathrm{~B}) \subset$

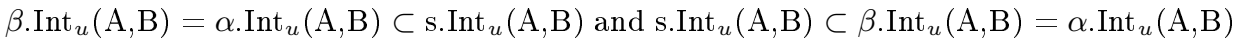
$\subset$ p.Int $_{u}(\mathrm{~A}, \mathrm{~B})$. So, p.Int ${ }_{u}(\mathrm{~A}, \mathrm{~B})=\mathrm{s} \cdot \operatorname{Int}_{u}(\mathrm{~A}, \mathrm{~B})$. Finally, we will show that the sets in (f) and $(\mathrm{c})$ are the only sets of coincidence points that can be obtained by use of the operator s.Int ${ }_{u}$. Since p.Int ${ }_{u}(\mathrm{~A}, \mathrm{~B})=\mathrm{s} \cdot \operatorname{Int}_{u}(\mathrm{~A}, \mathrm{~B})$ and $\alpha \cdot \operatorname{Int}_{u}(\mathrm{~A}, \mathrm{~B})=\beta \cdot \operatorname{Int}_{u}(\mathrm{~A}, \mathrm{~B})$ are equivalent, it is enough to prove that $\operatorname{sint}_{u}(\mathrm{~A}, \mathrm{~B})=\gamma \cdot \operatorname{Int}_{u}(\mathrm{~A}, \mathrm{~B}), \operatorname{s.Int}_{u}(\mathrm{~A}, \mathrm{~B})=\beta \cdot \operatorname{Int}_{u}(\mathrm{~A}, \mathrm{~B})$ and $\alpha \cdot \operatorname{Int}_{u}(\mathrm{~A}, \mathrm{~B})=\mathrm{p} \cdot \operatorname{Int}_{u}(\mathrm{~A}, \mathrm{~B})$ are equivalent. If $\mathrm{s} \cdot \operatorname{Int}_{u}(\mathrm{~A}, \mathrm{~B})=\gamma \cdot \operatorname{Int}_{u}(\mathrm{~A}, \mathrm{~B})$, then $\mathrm{Cl}\left(\right.$ p.Int $\left.{ }_{u}(\mathrm{~A}, \mathrm{~B})\right) \subset \mathrm{Cl}\left(\mathrm{s}^{-\operatorname{Int}_{u}}(\mathrm{~A}, \mathrm{~B})\right)$ which means $\mathrm{Cl}(\mathrm{B} \cap \operatorname{Int}(\mathrm{Cl}(\mathrm{A}))) \subset \mathrm{Cl}(\mathrm{B} \cap \mathrm{Cl}(\operatorname{Int}(\mathrm{A})))$ and implies that $\mathrm{Cl}(\operatorname{Int}(\mathrm{Cl}(\mathrm{A})))=\mathrm{Cl}(\operatorname{Int}(\mathrm{A}))$. So $\gamma \cdot \operatorname{Int}_{u}(\mathrm{~A}, \mathrm{~B})=(\mathrm{B} \cap \mathrm{Cl}(\operatorname{Int}(\mathrm{Cl}(\mathrm{A})))) \cup$ $(\mathrm{B} \cap \operatorname{Int}(\mathrm{Cl}(\mathrm{A})))=\beta \cdot \operatorname{Int}_{u}(\mathrm{~A}, \mathrm{~B})$ and consequently, $\operatorname{sint}_{u}(\mathrm{~A}, \mathrm{~B})=\beta \cdot \operatorname{Int}_{u}(\mathrm{~A}, \mathrm{~B})$. The last equality implies that $\mathrm{Cl}(\mathrm{B} \cap \mathrm{Cl}(\operatorname{Int}(\mathrm{Cl}(\mathrm{A}))))=\mathrm{Cl}(\mathrm{B} \cap \mathrm{Cl}(\operatorname{Int}(\mathrm{A})))$, so $\mathrm{Cl}(\operatorname{Int}(\mathrm{Cl}(\mathrm{A})))=$ $\mathrm{Cl}(\operatorname{Int}(\mathrm{A}))$ or equivalently, $\operatorname{Int}(\mathrm{Cl}(\mathrm{A}))=\operatorname{Int}(\mathrm{Cl}(\operatorname{Int}(\mathrm{A})))$. Thus, $\mathrm{B} \cap \operatorname{Int}(\mathrm{Cl}(\mathrm{A}))=\mathrm{B} \cap$

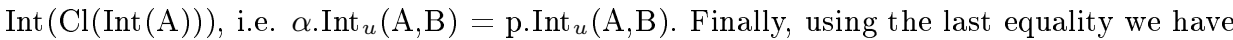
$\gamma \cdot \operatorname{Int}_{u}(\mathrm{~A}, \mathrm{~B})=(\mathrm{B} \cap \mathrm{Cl}(\operatorname{Int}(\mathrm{A}))) \cup(\mathrm{B} \cap \operatorname{Int}(\mathrm{Cl}(\operatorname{Int}(\mathrm{A}))))=\mathrm{B} \cap \mathrm{Cl}(\operatorname{Int}(\mathrm{A}))=\operatorname{s} \operatorname{Int}_{u}(\mathrm{~A}, \mathrm{~B})$, and the proof is complete.

The following diagram shows the relationship between the families of sets considered in the above theorem.

\section{Diagram 2.7.}

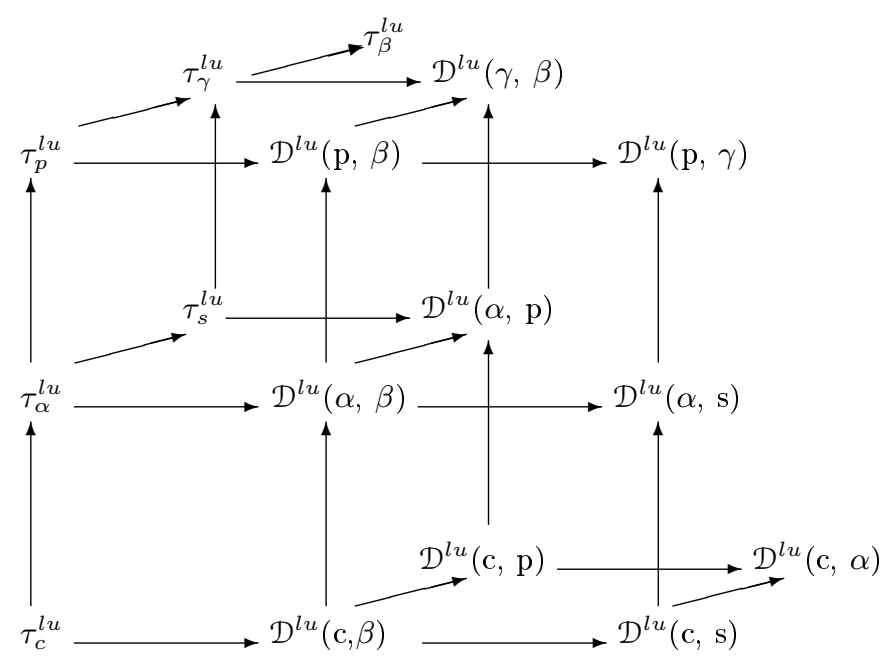


The next result follows directly from the definitions of the families of sets considered in Theorem 2.6 and, in the case (d), from the fact that the equalities $\operatorname{sint}_{u}(\mathrm{~A}, \mathrm{~B})=$

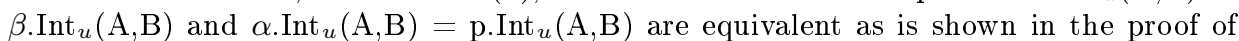
this theorem.

Theorem 2.8. For any topological space $(X, \tau)$, the following hold:

(a) $\tau_{c}^{l u}=\mathcal{D}^{l u}(\mathrm{c}, \alpha) \cap \tau_{\alpha}^{l u}=\mathcal{D}^{l u}(\mathrm{c}, \mathrm{s}) \cap \tau_{s}^{l u}=\mathcal{D}^{l u}(\mathrm{c}, \mathrm{p}) \cap \tau_{p}^{l u}=\mathcal{D}^{l u}(\mathrm{c}, \beta) \cap \tau_{\beta}^{l u}$;

(b) $\tau_{\alpha}^{l u}=\mathcal{D}^{l u}(\alpha, \mathrm{s}) \cap \tau_{s}^{l u}=\mathcal{D}^{l u}(\alpha, \mathrm{p}) \cap \tau_{p}^{l u}=\mathcal{D}^{l u}(\alpha, \beta) \cap \tau_{\beta}^{l u}$;

(c) $\tau_{p}^{l u}=\mathcal{D}^{l u}(\mathrm{p}, \gamma) \cap \tau_{\gamma}^{l u}=\mathcal{D}^{l u}(\mathrm{p}, \beta) \cap \tau_{\beta}^{l u}$;

(d) $\tau_{s}^{l u}=\mathcal{D}^{l u}(\alpha, \mathrm{p}) \cap \tau_{\beta}^{l u}$

(e) $\tau_{\gamma}^{l u}=\mathcal{D}^{l u}(\gamma, \beta) \cap \tau_{\beta}^{l u}$.

As a consequence of the above result we offer the following five decomposition theorems for multifunctions.

Theorem 2.9. For any multifunction $\mathrm{F}:(\mathrm{X}, \tau) \rightarrow(\mathrm{Y}, \xi)$, the following statements are equivalent:

(a) $\mathrm{F}$ is lu.s.c.;

(b) $\mathrm{F}$ is lu. $\alpha . c$. and $\mathcal{D}^{l u}(\mathrm{c}, \alpha)$-continuous;

(c) $\mathrm{F}$ is lu.q.c. and $\mathcal{D}^{l u}(\mathrm{c}, \mathrm{s})$-continuous;

(d) $\mathrm{F}$ is lu.p.c. and $\mathcal{D}^{l u}(\mathrm{c}, \mathrm{p})$-continuous;

(e) $\mathrm{F}$ is lu. $\beta$.c. and $\mathcal{D}^{l u}(\mathrm{c}, \beta)$-continuous.

Theorem 2.10. For any multifunction $\mathrm{F}:(\mathrm{X}, \tau) \rightarrow(\mathrm{Y}, \xi)$, the following statements are equivalent:

(a) $\mathrm{F}$ is lu. $\alpha . c$. ;

(b) $\mathrm{F}$ is lu.q.c. and $\mathcal{D}^{l u}(\alpha, \mathrm{s})$-continuous;

(c) $\mathrm{F}$ is lu.p.c. and $\mathcal{D}^{l u}(\alpha, \mathrm{p})$-continuous;

(d) $\mathrm{F}$ is lu. $\beta$.c. and $\mathcal{D}^{l u}(\alpha, \beta)$-continuous.

Theorem 2.11. For any multifunction $\mathrm{F}:(\mathrm{X}, \tau) \rightarrow(\mathrm{Y}, \xi)$, the following statements are equivalent:

(a) $\mathrm{F}$ is lu.p.c.;

(b) $\mathrm{F}$ is lu. $\gamma . c$. and $\mathcal{D}^{l u}(\mathrm{p}, \gamma)$-continuous;

(c) $\mathrm{F}$ is lu. $\beta$.c. and $\mathcal{D}^{l u}(\mathrm{p}, \beta)$-continuous.

Theorem 2.12. For any multifunction $\mathrm{F}:(\mathrm{X}, \tau) \rightarrow(\mathrm{Y}, \xi)$, the following statements are equivalent:

(a) $\mathrm{F}$ is lu.q.c.;

(b) $\mathrm{F}$ is lu. $\beta$.c. and $\mathcal{D}^{l u}(\alpha, \mathrm{p})$-continuous.

Theorem 2.13. For any multifunction $F:(X, \tau) \rightarrow(Y, \xi)$, the following statements are equivalent:

(a) $\mathrm{F}$ is lu. $\gamma . c$;

(b) $\mathrm{F}$ is lu. $\beta$.c. and $\mathcal{D}^{l u}(\gamma, \beta)$-continuous.

Remark 2.14. The classes of multifunctions corresponding to appropriate families of sets shown in the Diagram 2.7 are strictly different.

Proof. Let us consider some examples of multifunctions $\mathrm{F}:(R, \tau) \rightarrow(R, \xi)$, where $R$ is the set of all real numbers, $\tau$ denotes the natural topology on $R$ and $\xi$ is generated by the 
basis $\mathcal{B}_{\xi}=\{(-\infty, r): r \in R\}$. For a multifunction $\mathrm{F}$ and $\mathrm{W} \in \mathcal{B}_{\xi}$ we use the following notation: $\mathrm{A}_{W}=\mathrm{F}^{+}(\mathrm{W})$ and $\mathrm{B}_{W}=\mathrm{F}^{-}(\mathrm{W})$.

(i) Let $\mathrm{F}$ be defined as follows: $\mathrm{F}(0)=R, \mathrm{~F}(\mathrm{x})=\{-\ln (x)\}$ if $\mathrm{x}>0$ and $\mathrm{F}(\mathrm{x})=$ $\{-\ln (-x)\}$ if $\mathrm{x}<0$. If $\mathrm{W} \in \mathcal{B}_{\xi}$, then we have $\mathrm{A}_{W}=(-\infty,-\exp (-r)) \cup(\exp (-r)$, $+\infty), \mathrm{B}_{W}=\mathrm{A}_{W} \cup\{0\}$ and $\operatorname{Int}\left(\mathrm{A}_{W}\right)=\operatorname{Int}\left(\mathrm{Cl}\left(\mathrm{A}_{W}\right)\right)=\mathrm{A}_{W}$. So, $\mathrm{B}_{W} \cap \operatorname{Cl}\left(\operatorname{Int}\left(\mathrm{Cl}\left(\mathrm{A}_{W}\right)\right)\right)$ $=\operatorname{Int}\left(\mathrm{A}_{W}\right)$ but $\mathrm{B}_{W} \not \subset \mathrm{Cl}\left(\operatorname{Int}\left(\mathrm{Cl}\left(\mathrm{A}_{W}\right)\right)\right)$ and therefore $\mathrm{F}$ is $\mathcal{D}^{l u}(\mathrm{c}, \beta)$-continuous but not lu. $\beta . c$.

(ii) Let $\mathrm{F}$ be defined by $\mathrm{F}(0)=R, \mathrm{~F}(\mathrm{x})=\{\ln (x)\}$ if $\mathrm{x}>0$ and $\mathrm{F}(\mathrm{x})=\{\ln (-x)\}$ if $\mathrm{x}<0$ and let $\mathrm{W} \in \mathcal{B}_{\xi}$. Then we have $\mathrm{A}_{W}=(-\exp (r), 0) \cup(0, \exp (r)), \mathrm{B}_{W}=$ $\mathrm{A}_{W} \cup\{0\}, \operatorname{Int}\left(\mathrm{Cl}\left(\operatorname{Int}\left(\mathrm{A}_{W}\right)\right)\right)=\mathrm{B}_{W}$ but $\mathrm{B}_{W} \not \subset \operatorname{Int}\left(\mathrm{A}_{W}\right)$. So, $\mathrm{F}$ is lu. .c. but not $\mathcal{D}^{l u}(\mathrm{c}$, $\alpha)$-continuous.

(iii) Let us define $\mathrm{F}$ by $\mathrm{F}(0)=R, \mathrm{~F}(\mathrm{x})=\{-\ln (x)\}$ if $\mathrm{x}>0, \mathrm{~F}(\mathrm{x})=(-\infty,-\ln (-x))$ if $\mathrm{x} \in Q \cap(-\infty, 0)$ and $\mathrm{F}(\mathrm{x})=\mathrm{R} \backslash\{-\ln (-x)\}$ if $\mathrm{x} \in(-\infty, 0) \backslash Q$, where $\mathrm{Q}$ is the set of all rational numbers, and let $\mathrm{W} \in \mathcal{B}_{\xi}$. Then we have $\mathrm{A}_{W}=((-\infty,-\exp (-r)] \cap Q) \cup$ $(\exp (-r),+\infty), \mathrm{B}_{W}=(-\infty,-\exp (-r)] \cup((-\exp (-r), 0] \backslash Q) \cup\{0\} \cup(\exp (-r),+\infty)$. So $\operatorname{Int}\left(\mathrm{A}_{W}\right)=(\exp (-r),+\infty)$, and $\mathrm{Cl}\left(\mathrm{A}_{W}\right)=(-\infty,-\exp (-r)] \cup[\exp (-r),+\infty)$. So $\mathrm{B}_{W} \cap$ $\mathrm{Cl}\left(\operatorname{Int}\left(\mathrm{A}_{W}\right)\right) \subset \operatorname{Int}\left(\mathrm{A}_{W}\right)$ but $\mathrm{B}_{W} \cap \operatorname{Int}\left(\mathrm{Cl}\left(\mathrm{A}_{W}\right)\right) \not \subset \operatorname{Int}\left(\mathrm{A}_{W}\right)$ and $\mathrm{B}_{W} \cap \mathrm{Cl}\left(\operatorname{Int}\left(\mathrm{Cl}\left(\mathrm{A}_{W}\right)\right)\right.$ $\not \subset \operatorname{Int}\left(\mathrm{Cl}\left(\mathrm{A}_{W}\right)\right)$. Therefore, $\mathrm{F}$ is $\mathcal{D}^{l u}(\mathrm{c}, \mathrm{s})$-continuous but not $\mathcal{D}^{l u}(\mathrm{c}, \mathrm{p})$-continuous and not $\mathcal{D}^{l u}(\mathrm{p}, \beta)$-continuous.

(iv) Let us define $\mathrm{F}$ as follows: $\mathrm{F}(0)=R, \mathrm{~F}(\mathrm{x})=\{\ln (x)\}$ if $\mathrm{x}>0, \mathrm{~F}(\mathrm{x})=\{\ln (-x)\}$ if $\mathrm{x} \in Q \cap(-\infty, 0)$ and $\mathrm{F}(\mathrm{x})=[\ln (-x), \infty)$ if $\mathrm{x} \in(-\infty, 0) \backslash \mathrm{Q}$, where $\mathrm{Q}$ is the set of all rational numbers, and let $\mathrm{W} \in \mathcal{B}_{\xi}$. Then, $\left.\mathrm{A}_{W}=(-\exp (r), 0) \cap Q\right) \cup(0, \exp (r))$, $\left.\mathrm{B}_{W}=(-\exp (r)), \exp (r)\right), \operatorname{Int}\left(\mathrm{A}_{W}\right)=\operatorname{Int}\left(\mathrm{Cl}\left(\operatorname{Int}\left(\mathrm{A}_{W}\right)\right)=(0, \exp (r))\right.$ and $\operatorname{Int}\left(\mathrm{Cl}\left(\mathrm{A}_{W}\right)\right)=$ $(-\exp (r), \exp (r))=\mathrm{B}_{W}$. So $\mathrm{B}_{W} \subset \operatorname{Int}\left(\mathrm{Cl}\left(\mathrm{A}_{W}\right)\right)$ but $\mathrm{B}_{W} \cap \operatorname{Int}\left(\mathrm{Cl}\left(\mathrm{A}_{W}\right)\right) \not \subset \operatorname{Int}\left(\mathrm{Cl}\left(\operatorname{Int}\left(\mathrm{A}_{W}\right)\right)\right)$ and $\mathrm{B}_{W} \cap \mathrm{Cl}\left(\operatorname{Int}\left(\mathrm{A}_{W}\right)\right) \not \subset$

$\operatorname{Int}\left(\mathrm{Cl}\left(\operatorname{Int}\left(\mathrm{A}_{W}\right)\right)\right.$. Therefore, $\mathrm{F}$ is lu.p.c. but not $\mathcal{D}^{l u}(\alpha, \mathrm{p})$-continuous and $\mathrm{F}$ is not $\mathcal{D}^{l u}(\alpha, \mathrm{s})$-continuous.

(v) Let us define $\mathrm{F}$ the following way: $\mathrm{F}(0)=R, \mathrm{~F}(\mathrm{x})=\{\ln (-k)\}$ if $\mathrm{x} \in[k-1, k)$, where $\mathrm{k}=-1,-2, \ldots, \mathrm{F}(\mathrm{x})=\left\{\ln \left(-\frac{1}{n+1}\right)\right\}$ if $\mathrm{x} \in\left[-\frac{1}{n},-\frac{1}{n+1}\right)$, where $\mathrm{n}=1,2, \ldots, \mathrm{F}(\mathrm{x})$ $=\{\ln (k)\}$ if $\mathrm{x} \in(k, k+1]$, where $\mathrm{k}=1,2, \ldots$, and $\mathrm{F}(\mathrm{x})=\left\{\ln \left(\frac{1}{n+1}\right)\right\}$ if $\mathrm{x} \in\left(\frac{1}{n+1}, \frac{1}{n}\right]$ where $\mathrm{n}=1,2, \ldots$ Let $\mathrm{W} \in \mathcal{B}_{\xi}$. Then we have $\left.\mathrm{A}_{W}=[(-\exp (r)-\xi), \exp (r)+\xi)\right]-\{0\}$ and $\left.\mathrm{Cl}\left(\mathrm{A}_{W}\right)=\mathrm{Cl}\left(\operatorname{Int}\left(\mathrm{A}_{W}\right)\right)=\mathrm{Cl}\left(\operatorname{Int}\left(\mathrm{Cl}\left(\mathrm{A}_{W}\right)\right)\right)=\mathrm{B}_{W}=[(-\exp (r)-\xi), \exp (r)+\xi)\right]$ for some $\xi \in[0,1)$. So $\mathrm{B}_{W} \subset \mathrm{Cl}\left(\operatorname{Int}\left(\mathrm{A}_{W}\right)\right)$ but $\mathrm{B}_{W} \cap \mathrm{Cl}\left(\operatorname{Int}\left(\mathrm{Cl}\left(\mathrm{A}_{W}\right)\right)\right) \not \subset \operatorname{Int}\left(\mathrm{Cl}\left(\mathrm{A}_{W}\right)\right)$, and thus $\mathrm{F}$ is is lu.q.c. but not $\mathcal{D}^{l u}(\mathrm{p}, \beta)$-continuous.

(vi) Define $\mathrm{F}$ by $\mathrm{F}(\mathrm{x})=(-\infty,-x)$ for all $\mathrm{x} \in R$ and let $\mathrm{W} \in \mathcal{B}_{\xi}$. Then $\mathrm{A}_{W}=[-r,+\infty)$, $\mathrm{B}_{W}=R, \operatorname{Int}\left(\mathrm{A}_{W}\right)=\operatorname{Int}\left(\mathrm{Cl}\left(\mathrm{A}_{W}\right)\right)=(-r, \infty)$ and $\mathrm{Cl}\left(\operatorname{Int}\left(\mathrm{A}_{W}\right)\right)=\mathrm{A}_{W}$. Consequently, $\mathrm{B}_{W} \cap \operatorname{Int}\left(\mathrm{Cl}\left(\mathrm{A}_{W}\right)\right) \subset \operatorname{Int}\left(\mathrm{A}_{W}\right)$ but $\mathrm{B}_{W} \cap \mathrm{Cl}\left(\operatorname{Int}\left(\mathrm{A}_{W}\right)\right) \not \subset \operatorname{Int}\left(\mathrm{Cl}\left(\operatorname{Int}\left(\mathrm{A}_{W}\right)\right)\right)$. So, $\mathrm{F}$ is $\mathcal{D}^{l u}(\mathrm{c}$, p)-continuous but not $\mathcal{D}^{l u}(\alpha, \mathrm{s})$-continuous.

(vii) Let $\mathrm{F}$ be defined by $\mathrm{F}(0)=R, \mathrm{~F}(\mathrm{x})=\{\ln (x)\}$ if $\mathrm{x} \in Q \cap(0, \infty), \mathrm{F}(\mathrm{x})=$ $[\ln (x), \infty)$ if $\mathrm{x} \in(0, \infty) \backslash Q$ and $\mathrm{F}(\mathrm{x})=\{-\ln (-x)\}$ if $\mathrm{x}<0$. If $\mathrm{W} \in \mathcal{B}_{\xi}$, then we have $\mathrm{A}_{W}=(-\infty,-\exp (-r)) \cup((0, \exp (r)) \cap Q), \operatorname{Int}\left(\mathrm{A}_{W}\right)=(-\infty,-\exp (-r)), \mathrm{Cl}\left(\mathrm{A}_{W}\right)=$ $\mathrm{Cl}\left(\operatorname{Int}\left(\mathrm{Cl}\left(\mathrm{A}_{W}\right)\right)=(-\infty,-\exp (-r)] \cup[0, \exp (r)]\right.$ and $\mathrm{B}_{W}=(-\infty,-\exp (-r)) \cup[0, \exp (r))$. Thus $\mathrm{B}_{W} \subset \mathrm{Cl}\left(\operatorname{Int}\left(\mathrm{Cl}\left(\mathrm{A}_{W}\right)\right)\right.$ but $\mathrm{B}_{W} \not \subset \mathrm{Cl}\left(\operatorname{Int}\left(\mathrm{A}_{W}\right)\right) \cup \operatorname{Int}\left(\mathrm{Cl}\left(\mathrm{A}_{W}\right)\right.$, so $\mathrm{F}$ is lu. $\beta$.c. but not lu. .c.

\section{References}

[1] D. Andrijevic, Semi-preopen sets, Mat Vesnik. 38(1986), 24-32.

[2] D. Andrijevic, On b-open sets, Mat Bech. 48(1996),59-64. 
[3] A.A. El-Atik, A study of some types of mappings on topological spaces, Master's Thesis. Faculty of Science, Tanta University, (1997).

[4] C. Berge, Espaces topologiques fonctions multivaques, Dunod, Paris, (1959).

[5] C. Choquet, Lectures on Analysis, Benjamin, Vol. I, New York, Amsterdam (1969).

[6] J.P.R. Christensen, Theorems of J. Namioka and R.E.Johnson type for upper semicontinuous and compact-valued set-valued maps, Proc. Amer. Math. Soc. 86(1982), 649-55

[7] M.M. Coban, P.S. Kenderov, J.P. Revalski, Densely defined selections of multivalued mappings, Trans. Amer. Math. Soc. 344(1994), 533-552.

[8] S.G. Crossley, S.K. Hildebrand Semi-closure, Texas J. Sci. 22(1971), 99-112.

[9] J. Dontchev, M. Przemski, On the various decompositions of continuous and some weakly continuous functions, Acta Math. Hungar. 71(1996),109-120.

[10] E. Hatir, M. Caldas, On decompositions of continuity and $\alpha$-continuity, Arabian Journal for Science and Engineering 35(2010),197-202 .

[11] S. Kempisty, Sur les functions quasicontinues, Fund. Math., 19(1932), 184-197.

[12] M. Lassonde, J. Revalski, Fragmentability of sequences of set-valued mappings with applications to variational principles, Proc. Amer. Math. Soc. 133(2005), 2637-46.

[13] K. Kuratowski, Topology, I, New York (1966).

[14] N. Levine, Semi-open sets and semi-continuity in topological spaces, Amer. Math. Monthly, 70 (1963), 36-41 .

[15] A.S. Mashhour, I.A. Hasanein, S.N. El-Deeb, $\alpha$-continuous and $\alpha$-open mappings, Acta Math. Hungar., 41(1983), 213-218.

[16] A.S. Mashhour, M.E. El-Monsef, S.N. El-Deeb, On precontinuous and weak precontinuous mappings, Proc. Phys. Soc. Egypt 53(1982), 47-53 .

[17] M.E. El-Monsef, S.N. El-Deeb, R.A. Mahmoud, $\beta$-Open sets and $\beta$-continuous mappings, Bull. Fac. Sci. Assiut Univ. 12(1983), 77-90 .

[18] M.E. El-Monsef, M.E. Abd El-Monsef, A.A. Nasef, On multifunctions, Chaos, Solutions and Fractals, 12(2001), 2387-94 .

[19] W.B. Moors, J.R. Gilas, Generic continuity of minimal set-valued mappings, J. Austral. Math.Soc. Ser. A 63(1997), 238-62.

[20] T. Neubrunn, Strongly quasi-continuous multivalued mappings, Gen. Top. and its Rel. Mod. Anal. Algebra VI(1988), 351-59.

[21] O. Njastad , On some classes of nearly open sets, Pacific J. Math. 15(1965), 961-70.

[22] V.I. Ponomarev, Properties of topological spaces preserved under multivalued continuous mappings on compacta, Amer. Math. Soc. Trans. 38(2)(1964), 119-140 .

[23] T. Noiri, V. Popa, On decompositions of continuity in topological spaces, Acta Mathematica Hungarica 128 (2010),175-189.

[24] V. Popa, Some properties of H-almost continuous multifunctions, Problemy Mat. 10(1990), 9-26.

[25] V. Popa, On a decomposition of quasicontinuity for multifunctions, Stud. Cerc. Mat. 27(1975), 323-328 .

[26] V. Popa, T. Noiri, On upper and lower $\beta$-continuous multifunctions, Real Analysis Exchange 22(1996/97), 362-367.

[27] M. Przemski, A decomposition of continuity and $\alpha$-continuity, Acta Math. Hungar. 61(1993), 93-98 .

[28] M. Przemski, On the relationships between the graphs of multifunctions, Demonstratio Math. 41(2008), 203-224. 